\title{
Human Factors/Ergonomics in eWorld: methodology, techniques and applications
}

\author{
Oleksandr Burov \\ Institute of Information Technologies and Learning Tools \\ of National Academy of Educational Sciences of Ukraine, \\ 9 M. Berlyns'koho st., 04060, Kyiv, Ukraine \\ ayb@iitlt.gov.ua
}

\begin{abstract}
The analysis of ergonomic properties has been made in relation to ergonomic evaluation of objects of digital world. The proposal is to extent three recognized domains of Ergonomic (physical, cognitive and organizational) by the new one: informational. Some appropriate related topics are proposed. Information/cyber security issues are formulated as ergonomic objects in the digital environment. It is propose to add to four recognized general ergonomic properties (learnability, serviceability, controllability, inhabitability) to add resilience of human-system integration as one more ergonomic property. The technique to measure "ergonomicity" are discussed with the appropriate 4-point scale that is based on use of 4 levels of ergonomic indices: integral complex, group and single.
\end{abstract}

Keywords: Human Factors · Ergonomic properties - Ergonomic domains $\cdot$ Ergonomicity scale

\section{Introduction}

Ergonomics discipline promotes a holistic, human-centered approach to work systems design that considers the physical, cognitive, social, organizational, environmental, and other relevant factors independently on time and space of a human activity, and on a particular technology used [1]. It is world-recognized that changes in technologies led to that we live in digital world (eWorld), where not only compatibility of all components of the human-machine-environment system (HMES) can be critical, but the processes inside the HMES (information exchange, production of new information etc.) play more and more significant role. Information obtained by the humanin-the-loop needs to be described not only by volume and flow rate ("external" characteristics), but its (cognitive) content ("internal"). This is accompanied by changes in the nature of HMES components where information became both tool ("machine") and environment at the same time. Besides, the network, where the human and the system activity are carried out, has new features [2]. Information content became the tool to impact on the human and (as a tool in HMES) could be an object for ergonomics intervention.

It is recognized that the System changes its feature over last decades [3], especially in digital space, and a human individual cognitive, creative and critical abilities became crucial for the humanity civilization [4]. Today's children were born, grow, study, master their occupation, live and work in the world is increasingly losing the 
features of the material world and turning into the world of information and knowledge [5]. Taking into account the life-long learning trend in job market's needs, education and work become the mixed (to some extent) system of a new type - the system for production of knowledge and human talent as the intellectual capital. Because such a system has its own structure and functions, the general system performance can be described in terms of the systemic-structural activity theory [6].

Purpose. To analyze features and specifics of ergonomics challenges in the digital age as well as a human ergonomic needs in the eWorld.

\section{Discussion of results}

The transformation of the role of information networks, their place in life led to a shift of attention of networks' designers towards human-centric nature of their creation and existence, the emergence of the need to use the concept of not only the "integration network", but the concept of "integrated person-centric network" with its corresponding features [2]. Integrated network is not a new type of passive element of innovative processes and active, because it is much more clearly manifests the changing nature of modern art, which is "currency" with its own laws of formation, development, traffic and the need to protect [7], especially when working in information environment [8].

It is recognized that the most often cited domains of specialization within HFE are physical, cognitive and organizational ergonomics (Fig.1), where cognitive ergonomics focuses on mental activity. Above mentioned challenges can look like the cognitive ergonomics' domain, but the latter focuses on mental processes, and work in digital environment deals with content of the mental activity rather than with only the process of information flow. Ergonomics from the past to the present dealt with material world outside a human (even if mental processes reflected that world). Today's life and activity aims to a human brain and cognitive model of the world, because they produce new facts, new information and knowledge that can change the material world (mWorld).

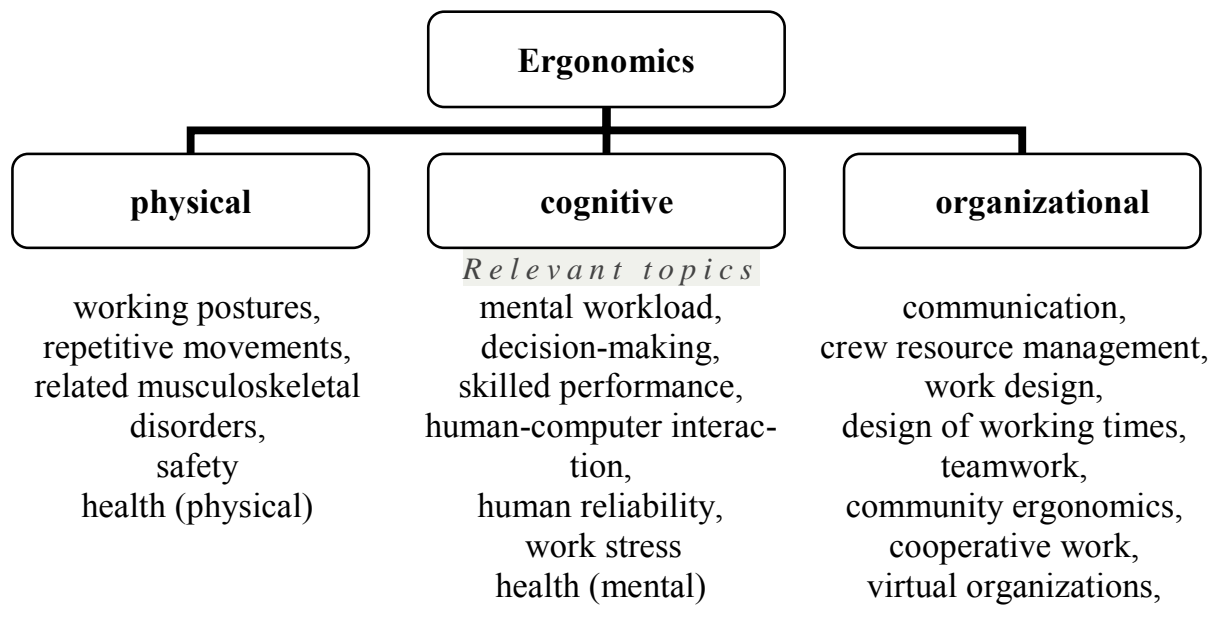


training

telework,

quality management

Fig. 1. Ergonomic domais and relevant topic (https://iea.cc) in digital world.

At the same time, Ergonomics can be interpreted as the scientific discipline that study human, tools, environment and their interaction in activity (Fig. 2).

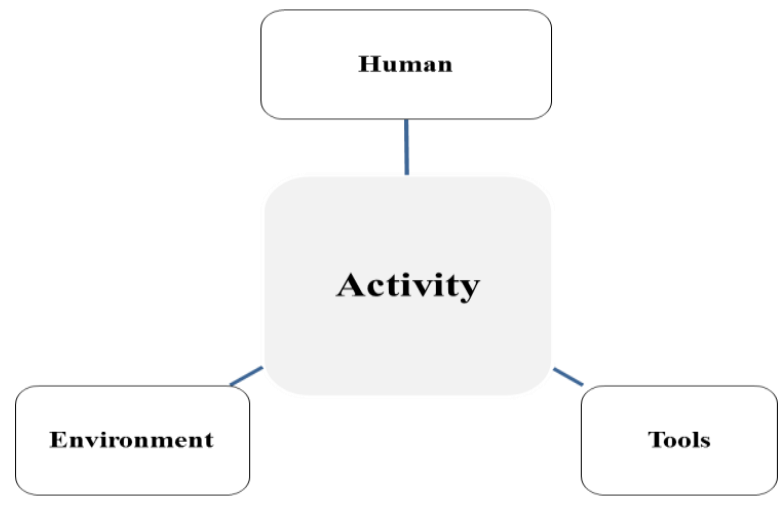

Fig.2. Subject of Ergonomics

Enviroment is considered as not only natural (physical, chemical, biological) one, but item (human made), organizational, psychological, informational. Respectively, above mentioned Ergonomics domains can be associated with one or two types of environment. But in digital world we faced new challenges related to the specific role of information that represents human, tools/means and environment at the same time, and that cannot be separated from a human (as an external object of his/her activity).

"Information ergonomics" can be discussed as a new specialization within Human Factors/Ergonomics, and its relevant topics are: parameters of information stream perceived by the senses, emotional importance of the information for human activity, perceived and unperceivable by consciousness, density and pace, controlled and uncontrolled. The ergonomic problem is the possibility of assessing the hazard of information for a human life and activity, as well as the possibility of protecting against it or mitigating its negative impact, as well as to develop the information security culture [9].

Depending on the means of action, the problems (and appropriate means) of infromation/cyber security can be classified into five groups:

- Legal,

- Technical,

- Information,

- Organizational,

- Psychological.

The legal issues of cybersecurity are handled by specialized experts and organizations, so they are not addressed in this article.

Information tools can be categorized according to the tasks solved by the users: 
- Protection/Remedies,

- Informing,

- Content,

- Learn how to use,

- Security,

- Life-span,

- Avoiding threats.

In the broadest sense possible targets for the impact of information/cyber security (in addition to critical infrastructure objects) can be:

- Databases

- Personal data, including financial

- Mass media

- Social networks

- Education and Training

- Textbooks, Historiographic editions.

Organizational tools for solving information/cyber security issues:

- informing,

- learning the culture of cybersecurity, professional staff of $\mathrm{KB}$ and the general population;

- creation of special means of the BC,

- distribution of KB facilities,

- control of use. level:

Psychological means can be grouped depending on the personal and interpersonal

- national,

- public,

- group,

- individual,

- cultural,

- cognitive,

- intellectual,

- habits.

One of the possible ergonomic ways to assist HMES design is discussed accounting above mentioned features of information with regards to a human safety, efficiency and comfort (wellbeing). Special attention in this regards should be paid to a human-integration system from point of view of the human.

How to measure the "ergonomicity" (ergonomic quality) of the HMES design for a human digital activity in eWorld?

It is proposed to discuss HMES' ergonomic properties (learnability, serviceability, controllability, inhabitability, resilience as well as cognitivity) and ergonomics indices to measure them (integral "ergonomicity", complex indices, group indices and single indices).

It is proposed the technique that uses measurable single indicators and those assessed by questionnaire (united in special group indices), group indices combined in complex indices ("ergonomic properties") accounting weights, and calculation of the 
integral "ergonomicity" (Table 1 ) that is normalized on a scale $[0,1]$. This technique has been implemented in the form of ICT tools.

Table 1. Ergonomic indices

\begin{tabular}{|c|c|c|c|c|c|}
\hline Level & \multicolumn{5}{|c|}{ Name } \\
\hline Integral & \multicolumn{5}{|c|}{ Ergonomicity } \\
\hline Complex & \multicolumn{5}{|c|}{ Ergonomic properties } \\
\hline & learnability & serviceability & controllability & inhabitability & resilience \\
\hline $\begin{array}{l}\text { Group } \\
\text { (exam- } \\
\text { ples) }\end{array}$ & $\begin{array}{l}\text { Learning } \\
\text { time, under- } \\
\text { standing of } \\
\text { instruction, } \\
\text { additional } \\
\text { question } \\
\text { need }\end{array}$ & $\begin{array}{l}\text { Access to } \\
\text { necessary } \\
\text { tools, con- } \\
\text { venience }\end{array}$ & $\begin{array}{l}\text { Visibility, } \\
\text { opportunity } \\
\text { to change } \\
\text { parameters }\end{array}$ & $\begin{array}{l}\text { Interface } \\
\text { comfort, } \\
\text { optimal } \\
\text { parameters } \\
\text { for human } \\
\text { sensors }\end{array}$ & $\begin{array}{l}\text { Ability to } \\
\text { restore } \\
\text { perfor- } \\
\text { mance } \\
\text { after } \\
\text { damage }\end{array}$ \\
\hline $\begin{array}{l}\text { Single } \\
\text { (exm- } \\
\text { ples) }\end{array}$ & $\begin{array}{l}\text { Longevity of } \\
\text { effective } \\
\text { learning, } \\
\text { scope of } \\
\text { instruction }\end{array}$ & $\begin{array}{l}\text { Number of } \\
\text { objects in } \\
\text { working } \\
\text { field, access } \\
\text { to adjust- } \\
\text { ment }\end{array}$ & $\begin{array}{l}\text { Optimal } \\
\text { vision of } \\
\text { necessary } \\
\text { items, con- } \\
\text { trol panel }\end{array}$ & $\begin{array}{l}\text { Comfort } \\
\text { colours pal- } \\
\text { ette, size of } \\
\text { items }\end{array}$ & $\begin{array}{l}\text { Time to } \\
\text { re-start, } \\
\text { full recov- } \\
\text { ery }\end{array}$ \\
\hline
\end{tabular}

After calculation of number of critical single indices, the group, complex and integral indices are calculated in relation to the maximal numbers of corresponding indices. The integral ergonomicity is evaluated as the 4-point scale:

\begin{tabular}{|c|c|}
\hline Value & Ergonomicity \\
$0.75 \ldots 1.0$ & $\begin{array}{r}\text { Corresponds the best ergonomic designs } \\
0.5 \ldots 0.75\end{array}$ \\
$0.25 \ldots 0.5$ & $\begin{array}{r}\text { Good ergonomicity, but some parameters } \\
\text { need to be improved }\end{array}$ \\
$<0.25$ & Relative ergonomicity. Need to re-design \\
\end{tabular}


Similar evaluation are made for every ergonomic property and could be used to compare the particular object of evaluation with competing ones, as well as for improving of ergonomic quality of the object.

\section{Conlusion}

The analysis of ergonomic properties has been made in relation to ergonomic evaluation of objects of digital world. The proposal is to extent three recognized domains of Ergonomic (physical, cognitive and organizational) by the new one: informational. Some appropriate related topics are proposed.

Information/cyber security issues are formulated as ergonomic objects in the digital environment.

It is propose to add to four recognized general ergonomic properties (learnability, serviceability, controllability, inhabitability) to add resilience of human-system integration as one more ergonomic property.

The technique to measure "ergonomicity" are discussed with the appropriate 4point scale that is based on use of 4 levels of ergonomic indices: integral complex, group and single.

Acknowledgments. This research has been supported by the Institute of Information Technologies of the National Academy of Pedagogic Science.

\section{References}

1. Karwowski, W.: The discipline of human factors and ergonomics. Handbook of human factors and ergonomics, 4, 3-37 (2012).

2. Burov, O.: Virtual Life and Activity: New Challenges for Human Factors/Ergonomics. In: Symp. Beyond Time and Space STO-MP-HFM-231, STO NATO, pp. 8-1...8-8 (2014).

3. Wilson John R., Carayon Pascale: Systems ergonomics: Looking into the future - Editorial for special issue on systems ergonomics/human factors. Applied Ergonomics. Volume 45, Issue 1, 3-4, (2014).

4. Strategies for the New Economy Skills as the Currency of the Labour Market. Report. $\begin{array}{lllll}\text { World } & \text { Economic } & \text { Forum. } & 22 & \text { January }\end{array}$ https://www.weforum.org/whitepapers/strategies-for-the-new-economy-skills-as-thecurrency-of-the-labour-market Davos (2019).

5. Pinchuk O., Lyvynova S., Burov O.: Synthetic educational environment - a footpace to new education / O. Pinchuk, S. Lyvynova, O. Burov // Informacijni tekhnologhiji i zasoby navchannja: elektronne naukove fakhove vydannja, V.60, № 4, 28--45 (2017) in Ukrainian

6. Bedny, G. Z., \& Karwowski, W.: A Systemic-Structural Activity Approach to the Design of Human-Computer Interaction Tasks. International Journal of Human-Computer Interaction, 16(2), 235-260 (2003). 
7. Burov O.Ju.: Educational Networking: Human View to Cyber Defense. Institute of Information Technologies and Learning Tools 52, 144--156 (2016).

8. Da Veiga, A., Martins, N.: Information security culture and information protection culture: a validated assessment instrument. Comput. Law Secur. Rev. 31(2), 243-256 (2015).

9. Glaspie H.W., Karwowski W. (2018) Human Factors in Information Security Culture: A Literature Review. In: Nicholson D. (eds) Advances in Human Factors in Cybersecurity. AHFE 2017. Advances in Intelligent Systems and Computing, vol 593. Springer, Cham. 